\title{
Laser endopyelotomie voor een zeldzame vorm van ureterobstructie na niertransplantatie
}

\author{
Benjamin H. J. Doornweerd ${ }^{1}$ Stijn Roemeling ${ }^{1}$
}

Published online: 19 September 2016

(C) The Author(s) 2016. This article is available at SpringerLink with Open Access.

Samenvatting Een obstructie van de proximale ureter is een zeldzame complicatie na niertransplantatie. Twee casus worden beschreven, waarin een functionele obstructie behandeld wordt met laser endopyelotomie. Dit is een veilige procedure en de behandeling is succesvol.

Trefwoorden niertransplantatie pyelo-ureterale overgangsstenose $\cdot$ endopyelotomie $\cdot$ holmium-YAG

\section{Laser endopyelotomy for a rare form of ureteral obstruction after kidney transplantation}

\begin{abstract}
Obstruction of the proximal ureter is a rare complication after renal transplantation. Two cases are described in which functional obstruction has been treated with laser endopyelotomy. This is a safe procedure and a successful result has been achieved.
\end{abstract}

Keywords kidney transplantation · pelvi-ureteric junction obstruction $\cdot$ endopyelotomy $\cdot$ holmium-YAG

\section{Introductie}

Niertransplantatie is de eerste keuze als nierfunctievervangende therapie; patiënten hebben na niertransplantatie een betere overleving dan patiënten die dialyseren [1]. De meest voorkomende urologische complicatie van niertransplanta-

drs. Benjamin H. J. Doornweerd

b.h.j.doornweerd@umcg.nl

1 afdeling Urologie, Universitair Medisch Centrum Groningen, Groningen, Nederland tie is obstructie van de getransplanteerde ureter. De meeste obstructies van de ureter treden op in de distale ureter; stenoses ter plaatse van de proximale ureter en de pyelo-ureterale overgang worden ook beschreven, maar zijn zeldzaam [2-6].

We beschrijven twee casus waarbij een functionele obstructie op het niveau van de proximale ureter optrad na niertransplantatie.

\section{Casus 1}

De eerste casus betreft een 31-jarige vrouwelijke patiënt met congenitaal dysplastische nieren. Op driejarige leeftijd startte zij met peritoneale dialyse; een eerste en tweede niertransplantatie vonden plaats op vier- en zesjarige leeftijd, die beide werden gecompliceerd door rejectie. Een derde niertransplantatie vond plaats op 25-jarige leeftijd. Het betrof de rechternier van een levende, verwante donor, welke in de rechter fossa iliaca werd getransplanteerd. Er werd een eindstandige ureterovesicale anastomose aangelegd, zonder antirefluxmechanisme. De anastomose werd tijdelijk gestent met een uretersplint. Het beloop was ongecompliceerd, en de functie van de getransplanteerde nier was goed.

Acht jaar na transplantatie trad plotseling nierfunctieverslechtering op. In verband met een zwangerschapswens werd de immuunsuppressieve medicatie aangepast, waarbij het mycofenolaat mofetil werd vervangen voor azathioprine. De gemeten kreatinineklaring bleek in een week tijd gedaald van $60 \mathrm{ml} / \mathrm{min}$ naar $32 \mathrm{ml} / \mathrm{min}$. Echografie van de nier liet hydronefrose zien. Retrograde ureteropyelografie toonde een uitgezet pyelocalicieel systeem, met een nietgedilateerde ureter en een ogenschijnlijk nauwe pyelo-ureterale overgang. Er waren geen aanwijzingen voor stenen 


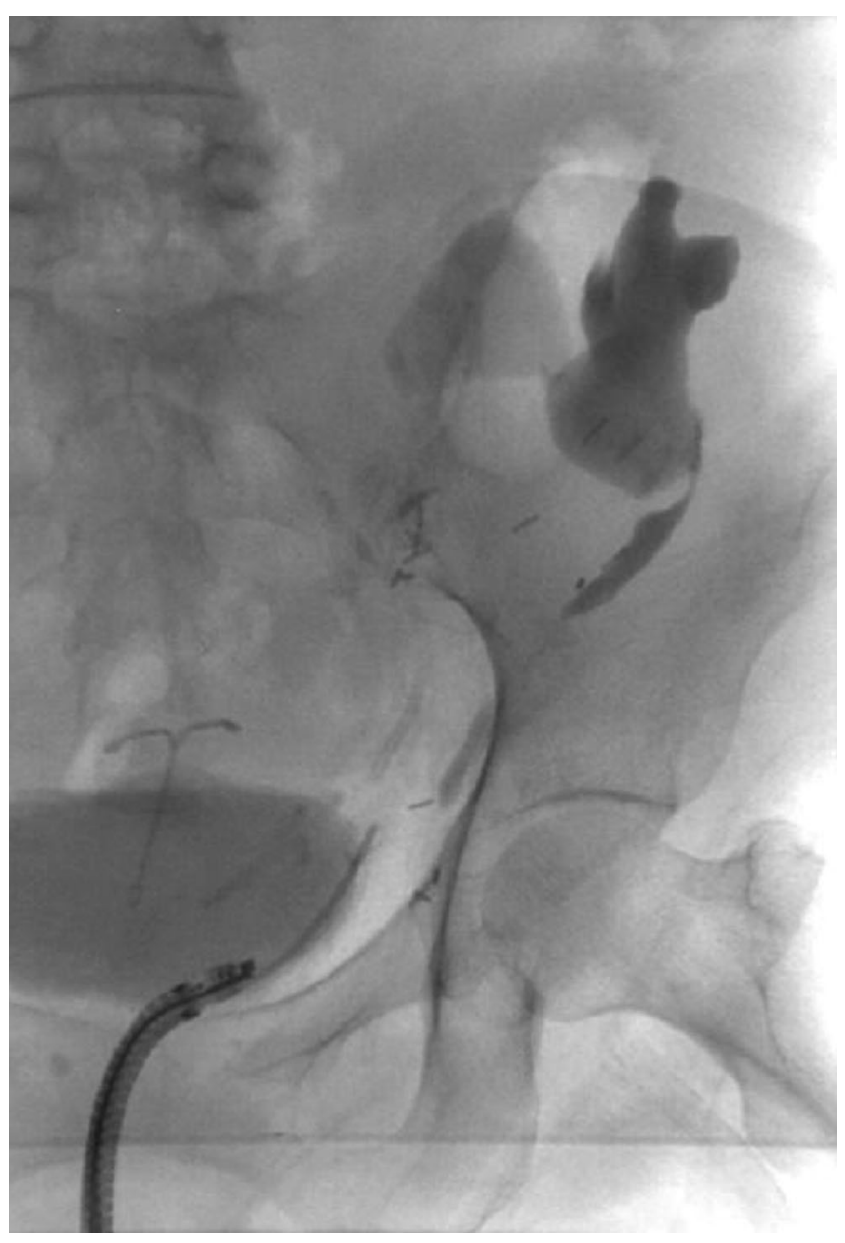

Figuur 1 Retrograde ureteropyelografie voorafgaand aan de endopyelotomie. Ter plaatse van de pyelo-ureterale overgang wordt een nauw segment gezien, dat bij ureterorenoscopie blijkt te berusten op een scherpe hoek en niet op een intrinsieke obstructie.

of tumoren. Een dubbel-J-katheter werd ingebracht, waarna de nierfunctie herstelde tot het oude niveau.

Besloten werd tot een diagnostische ureterorenoscopie. Daarop waren geen intraluminale afwijkingen gezien en met name niet het beeld dat past bij een klassieke pyelo-ureterale overgangsstenose. De flexibele ureteroscoop kon eenvoudig worden opgevoerd tot in het pyelum. Ter plaatse van de pyelo-ureterale overgang moest daarvoor een scherpe hoek worden gepasseerd. Empirisch verwijderen van de JJkatheter leidde tot anurie en opnieuw hydronefrose. Een mercaptoacetyltriglycine (MAG3) renogram was niet conclusief voor de afvloed, in verband met vertraagde opname. De dubbel-J-katheter werd herplaatst, waarna een reconstructief plan werd gemaakt. Een MRI-scan van het abdomen liet geen compressie van de ureter zien. Daarnaast kon de anatomie van de nierarterie en niervene vastgelegd worden. De ureter bleek dorsocaudaal van de vasculaire hilus te verlopen. Hieruit werd geconcludeerd dat het beloop van de vaten geen bijdrage leverde aan de afvloedbelem- mering en dat ter plaatse van de scherpe knik in de ureter geen gevaar zou bestaan voor letsel van de nierarterie of niervene.

Onder algehele anesthesie en antibiotische profylaxe vond een endopyelo(uretero)tomie plaats met de holmium yttrium-aluminium-garnet (Ho:YAG) laser. De scherpe hoek ter plaatse van de pyelo-ureterale overgang werd aan de mediale zijde over een lengte van circa $15 \mathrm{~mm}$ geïncideerd tot in het periureterale vet. Een Ch6-tandem dubbel-J-katheter werd geplaatst, welke na vier weken werd verwijderd, waarna de nierfunctie stabiel bleef en geen hydronefrose optrad.

Op een controle-ureterorenoscopie was een fraai genezen incisie te zien met een ruime doorgang van ureter naar pyelum. Drie en zes maanden postoperatief bleek de nierfunctie onverminderd stabiel.

\section{Casus 2}

Een 53-jarige vrouw met nierinsufficiëntie door een idiopathische glomerulopathie onderging een tweede niertransplantatie. De rechternier van een postmortale donor werd getransplanteerd in de linker fossa iliaca. Er werd gebruikgemaakt van een (eenvoudige) ureterovesicale anastomose zonder antirefluxmechanisme.

Vijf dagen na de transplantatie trad een verslechtering van de nierfunctie op, terwijl de dubbel-J-katheter zich nog in situ bevond. Echografie van de nier toonde hydronefrose en er werd een percutane nefrostomiekatheter geplaatst. Er liep urine af onder hoge druk en de nierfunctie herstelde zich. Na een accidentele dislocatie van de nefrostomiekatheter werd opnieuw een dubbel-J-katheter geplaatst. Retrograde ureteropyelografie toonde een gedilateerd pyelocalicieel systeem met een nauw gedeelte in de proximale ureter, net distaal van de pyelo-ureterale overgang. Opvallend was daarnaast de positionering van de nier, waarbij de kelkhalzen naar mediaal gericht bleken (fig. 1).

$\mathrm{Bij}$ een diagnostische ureterorenoscopie waren geen intraluminale afwijkingen te zien en het pyelum kon eenvoudig bereikt worden. Ter plaatse van de proximale ureter moest hiervoor een scherpe bocht gepasseerd worden. Een MRI-scan van het abdomen toonde geen compressie van de ureter en de nierhilus kon worden geïdentificeerd. De nierarterie en niervene verliepen naar caudaal, richting iliacale vaten. Het pyelum lag naar ventraal en de ureter verliep naar laterocaudaal. Ter plaatse van de proximale ureter werd geen contact van het verzamelsysteem met de vasculatuur gezien.

Onder algehele anesthesie en antibiotische profylaxe vond een endopyelotomie plaats met behulp van Ho:YAGlaser. Aan mediale zijde werden de pyelo-ureterale overgang en proximale ureter over een lengte van circa $15 \mathrm{~mm}$ 


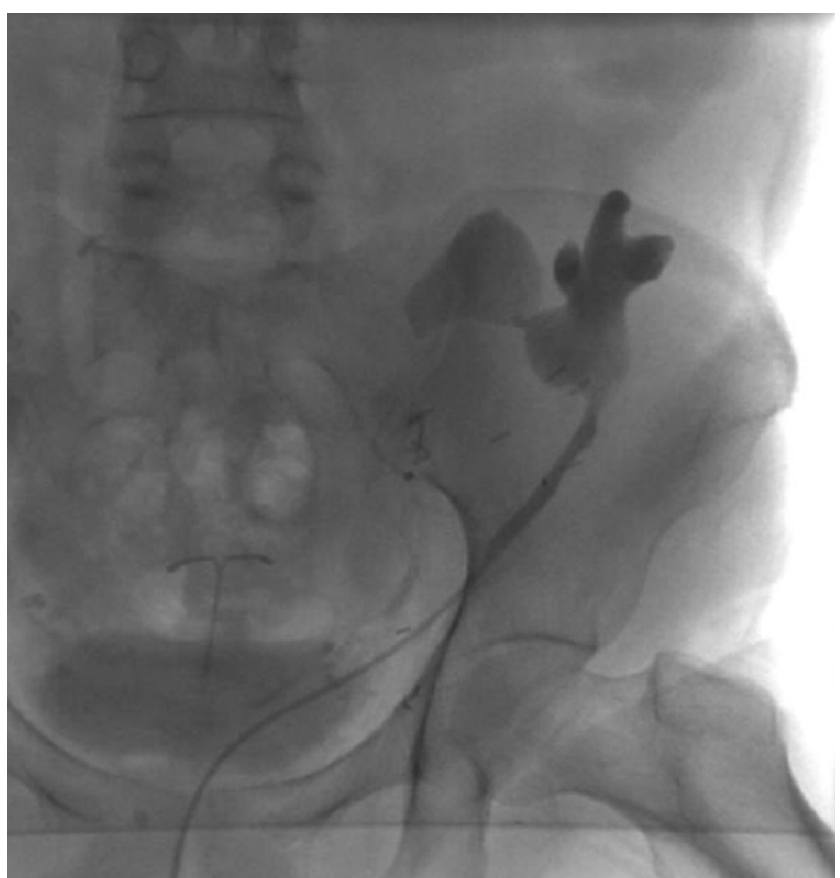

Figuur 2 Retrograde ureteropyelografie vier weken na endopyelotomie. Er wordt geen vernauwing meer gezien.

geïncideerd tot in het periureterale vet. Postoperatief werd een Ch10-endopyelotomie dubbel-J-katheter geplaatst.

Vier weken later werd de peroperatief geplaatste dubbelJ-katheter verwijderd. Op een controle-retrograde ureteropyelografie (fig. 2) en ureterorenoscopie waren een doorgankelijke ureter en pyelo-ureterale overgang gezien. Drie maanden postoperatief bleek de hydronefrose verdwenen en zes maanden postoperatief bleek de nierfunctie onverminderd stabiel.

\section{Discussie}

In deze twee casus werd een afvloedbelemmering na niertransplantatie succesvol behandeld met Ho:YAG-laser endopyelo-ureterotomie. In beide casus was sprake van een knik in de proximale ureter en, op basis hiervan, een functionele obstructie. In de tweede casus was de obstructie een direct gevolg van de positionering van de nier tijdens transplantatie. In de eerste casus is onopgehelderd gebleven waarom deze complicatie zich acht jaar na transplantatie voordeed, al lijkt de positionering van de nier ook hier een rol te spelen. Bij beide patiënten is de procedure ongecompliceerd verlopen en in beide gevallen was er op korte termijn sprake van adequate afvloed van de getransplanteerde nieren. Langetermijnfollow-up ontbreekt nog.

Ureterobstructie is de meest voorkomende urologische complicatie na niertransplantatie. Meestal betreft het een obstructie van de distale ureter of van de ureterovesicale overgang. In een klein aantal gevallen is er sprake van een stenose ter plaatse van de proximale ureter of pyeloureterale overgang $[2-4,6]$. Deze obstructies worden toegeschreven aan littekenvorming en knikken van de ureter. De behandeling kan bestaan uit een open procedure met bijvoorbeeld het ontknikken van de ureter [4], pyelo-ureterostomie met gebruikmaking van de ipsilaterale, natieve ureter of een pyelumplastiek [3, 6]. Minimale invasieve alternatieven zijn antegrade cold knife endopyelotomie [7] en monopolaire elektro-incisie met ballondilatatie (Acucise) [8-10]. Gdor et al. beschrijven een drietal patiënten bij wie pyelo-ureterale overgangsobstructie bij getransplanteerde nieren optrad, die allen werden behandeld met Ho:YAG-laser endopyelotomie. Zij schrijven de oorzaak van de obstructie toe aan knikken van de ureter en behalen met hun behandeling een succespercentage van 100 [11].

Hoewel een afwijkende positie van de nier een zeldzame complicatie is, komt uit onze casus het belang naar voren van een zorgvuldige positionering van de nier en de ureter ten tijde van de niertransplantatie.

\section{Conclusie}

Ho:YAG-laser endopyelo-ureterotomie van de proximale ureter en de pyelo-ureterale overgang na niertransplantatie, is een te overwegen alternatief voor open reconstructie bij functionele, proximale ureterstenoses.

Open Access This article is distributed under the terms of the Creative Commons Attribution 4.0 International License (http:// creativecommons.org/licenses/by/4.0/), which permits unrestricted use, distribution, and reproduction in any medium, provided you give appropriate credit to the original author(s) and the source, provide a link to the Creative Commons license, and indicate if changes were made.

\section{Literatuur}

1. Wolfe RA, Ashby VB, Milford EL, Akinlou OO, Ettenger RE, Agodoa LY, et al. Comparison of mortality in all patients on dialysis, patients on dialysis awaiting transplantation, and recipients of a first cadaveric transplant. N Engl J Med. 1999;341(23):1725-30.

2. Mundy AR, Podesta ML, Bewick M, Rudge CJ, Ellis FG. The urological complications of 1000 renal transplants. $\mathrm{Br} \mathrm{J}$ Urol. 1981;53(5):397-402.

3. Shoskes D, Hanbury D, Cranston D, Morris P. Urological complications in 1,000 consecutive renal transplant recipients. J Urol. 1995; 153:18-21.

4. Streeter EH, Little DM, Cranston DW, Morris PJ. The urological complications of renal transplantation: a series of 1535 patients. BJU Int. 2002;90:627-34.

5. Roijen JH van, Kirkels WJ, Zietse R, Roodnat JI, Weimar W, Ijzermans JNM. Long-term graft survival after urological complications of 695 kidney transplantations. J Urol. 2001;165:1884-7.

6. Whang M, Yballe M, Geffner S, Fletcher HS, Palekar S, Mulgaonkar S. Urologic complications in more than 2500 kidney transplan- 
tations peformed at the saint Barnabas healthcare system. Transplant Proc. 2011;43(5):1619-22.

7. Schumacher M, Studer UE, Danuser H. Antegrade endopyelotomy for treatment of ureteropelvic junction obstruction in transplanted kidneys. J Endourol. 2006;20(5):305-8.

8. Williams SG, McVigar JP, Low RK. Endopyelotomy for treatment of ureteropelvic junction obstruction caused by torsion of a renal allograft. J Urol. 1999;161:1560-1.

9. Seseke F, Heuser M, Zöller G, Plothe KD, Ringert RH. Treatment of iatrogenic postoperative ureteral strictures with Acucise endoureterotomy. Eur Urol. 2002;42(4):370-5, Oct.
10. Campschroer T, Lock M, Bosch J. Acucise ${ }^{\circledR}$ Endoureterotomy: a forgotten treatment option in ureteral strictures of benign origin between the ureteropelvic and ureterovesical junctions; long-term results. Urol Nephrol Open Access J. 2015;2(1):1-6.

11. Gdor Y, Gabr AH, Faerber GJ, Wolf JS. Holmium:yttrium-aluminum-garnet laser endoureterotomy for the treatment of transplant kidney ureteral strictures. Transplantation. 2008;85(9):1318-21.

drs. Benjamin H.J. Doornweerd uroloog

dr. Stijn Roemeling uroloog 


\section{Hier staat een advertentie.}

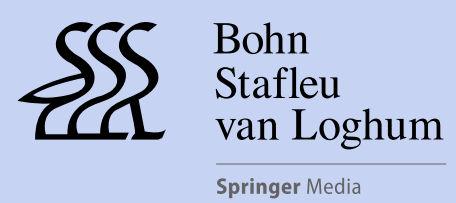

Houten 2017 


\section{Hier staat een advertentie.}

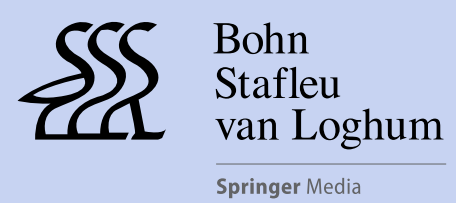

Houten 2017 


\section{Hier staat een advertentie.}

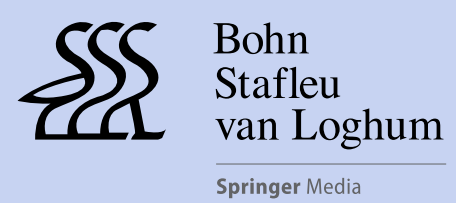

Houten 2017 


\section{Hier staat een advertentie.}

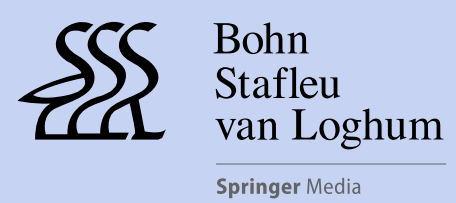

Houten 2017 